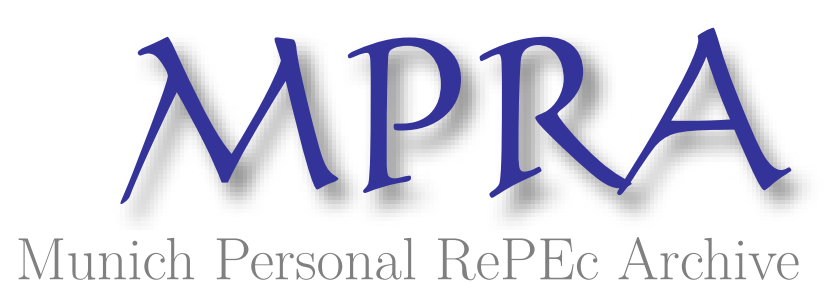

\title{
Spillovers and RD Incentive under Incomplete Information
}

Chatterjee, Rittwik and Chattopadhyay, Srobonti and Kabiraj, Tarun

Centre for Studies in Social Sciences Calcutta, Kolkata, Vidyasagar College for Women, Kolkata, Indian Statistical Institute, Kolkata

9 March 2018

Online at https://mpra.ub.uni-muenchen.de/85089/

MPRA Paper No. 85089, posted 11 Mar 2018 22:44 UTC 


\title{
Spillovers and R\&D Incentive under Incomplete
}

\author{
Information*
}

\author{
Rittwik Chatterjee ${ }^{\dagger}$ \\ Srobonti Chattopadhyay
}

Tarun Kabiraj ${ }^{\S}$

${ }^{*}$ Correspondence to: Tarun Kabiraj

${ }^{\dagger}$ Centre for Studies in Social Sciences Calcutta, Kolkata; Email: rittwik@gmail.com

${ }^{\ddagger}$ Vidyasagar College for Women, Kolkata; Email: srobonti@gmail.com

§Indian Statistical Institute, 203 B. T. Road, Kolkata - 700108, INDIA; Email: tarun@isical.ac.in; Tel.: +91-33-25752603; Fax: +91-33-25778893 


\title{
Spillovers and R\&D Incentive under Incomplete
}

\section{Information}

\begin{abstract}
Spillovers of R\&D outcome affect the R\&D decision of a firm. The present paper discusses the $R \& D$ incentives of a firm when the extent of $R \& D$ spillover is private information to each firm. We construct a two stage game involving two firms when the firms first decide simultaneously whether to invest in $R \& D$ or not, then they compete in quantity. Assuming general distribution function of firm types we compare R\&D incentives of firms under alternative scenarios based on different informational structures. The paper shows that while $R \& D$ spillovers reduce $R \& D$ incentives under complete information unambiguously, however, it can be larger under incomplete information.
\end{abstract}

Keywords: R\&D incentives, Cournot duopoly, Spillovers, Incomplete information. JEL Classification: D43, D82, L13, O31. 


\section{Introduction}

Spillovers of $R \& D$ results are common phenomena in industries. Spillover, in most general terms, depicts a situation where there is an intentional or unintentional leakage of the R\&D results of a firm to other firms within or across industries. There is a large literature to show that the possibility of knowledge spillovers affects the $R \& D$ decision of a firm. In the presence of spillovers, firms tend to underinvest in $R \& D^{1}$. Perhaps that is why the firms very often get involved in a race for winning patents in order to secure their $R \& D$ output. Patent race is also widely studied in the $R \& D$ literature ${ }^{2}$.

However, it may not always be possible to get patent for every innovation. An innovation has to pass through multiple rounds of examinations so as to ascertain that the innovation is indeed an original one and that it does not have "substantial" overlapping with any prior patented innovation ${ }^{3}$. Thus even if it is possible to obtain a patent, getting a patent involves time. If obtaining a patent takes a longer bit of time, then by the time the patent is obtained, it may not serve the purpose of protecting the benefits of the innovation as other competing innovations may have come into being in the mean time. Another important fact is that even when patents are available, they are imperfectly enforced, and when a patent is infringed, proving the case is a lengthy process. Therefore, when patents are either not available or not effective enough to prevent appropriation of R\&D benefits by other firms, incentives of an innovating firm to undertake R\&D activities decline, hence firms tend to underinvest in R\&D both from industry and social point of view (Conti, 2014). Ornaghi (2006) has drawn attention to the existence of a possible gap between private and social rates of return of $R \& D$; this reflects insufficient appropriability from $R \& D$ investments. That a firm benefits from $R \& D$ of their rivals is also evident in Jaffe (1986) which provides empirical evidence of the presence of spillovers.

To further motivate the problem of non-appropriability of R\&D knowledge in the presence of spillovers consider research joint ventures (RJVs). As shown by d'Aspremont

\footnotetext{
${ }^{1}$ See, for instance, Katz (1986 ), d'Aspremont and Jacquemin (1988); Kamien et.al.(1992) ; and Suzumura (1992).

${ }^{2}$ See Shapiro (1985), Baye and Hoppe (2003), Baker and Mezetti (2005) etc.

${ }^{3}$ How much overlapping is allowed in case of issuing a fresh patent may vary from country to country or situation to situation.
} 
and Jacquemin (1988), RJV enhances the level of R\&D investment when spillovers are high. That is why in some countries the governments encourage RJVs for corporate research by giving direct subsidy, tax credit, and infrastructural support. It may also be noted that to promote RJVs among firms in the US, the National Cooperative Research Act was designed (Ghosh and Ghosh, 2014). However, it is not always possible to have RJVs because of moral hazard or other problems. Since RJVs may also lead to market concentration, at times they are prevented by anti-trust laws. Sometimes firms themselves may feel discouraged to enter RJVs since the resulting innovation keeps both the firms on equal footage, thus not providing enough competitive edge to firms over their rivals. Conti (2014), in particular, observes that due to asymmetries among firms, especially in terms of their sizes, the benefits of RJVs may be distributed unevenly, which is likely to create disincentives for collaboration among firms.

Now, given that there are spillovers, different firms may have different absorptive capacities depending on their size, past experiences and adapting capabilities (Kogut and Zander, 1992). This in turn determines the extent of spillovers of an innovation to be enjoyed by a firm. How much spillovers would occur for an innovation is likely to be a variable determining investment of an $R \& D$ firm. Such absorptive capacities have been termed as spillover parameters by Amir et.al. (2003). They not only study comparative performance of non-cooperative and cooperative $R \& D$ in presence of endogenous spillovers, but more importantly, characterise the structure of the R\&D cartels which endogenously determine the spillover rates. However, the spillover parameters which are in effect, the absorptive capacities of firms determined endogenously, can very well be private information, i.e. privately known to the concerned firms. Therefore in the presence of spillovers firms decide whether to invest in R\&D or not depending on what information they have about their rivals' abilities to benefit from spillovers of R\&D knowledge. Hence the purpose of the present paper is to study the $R \& D$ incentive of a firm in a situation where R\&D spillover parameters of the firms are unknown. Each firm in our framework perfectly knows its own spillover parameter, that is the extent of R\&D output that gets spilled over to the firm from its rival; but depending on the informational structure, the 
firm may or may not know the spillover parameter of its rival since the ability to benefit from spillover of knowledge from other sources depends largely on endogenous factors of a firm, and these factors may not be perfectly observable to others. Accordingly, we are in the regime of complete or incomplete information. When every firm knows its own as well as its rival's spillover parameters, we have a complete information framework. When a firm can only observe its own spillover parameter but not of the rival's, we are in an incomplete information scenario. Clearly, under incomplete information the spillover parameters constitute types of the firms. This paper considers general distribution function of firm types.

The impact of spillovers on R\&D incentives in a complete information framework is well investigated in the literature. For instance, Reinganum (1981) notes that if the value of adopting a cost-reducing, capital embodied process innovation declines with the number of firms; then the adopting firms are induced to use newer technologies in a sequence and thus the knowledge gets diffused over time. Grilliches (1992) emphasises the importance of R\&D spillovers with supportive empirical evidence. Mookherjee and Ray (1991) consider the diffusion of the latest technology developed by a dominant firm to competitive fringe firms for both price and quantity competition in the product market. In their model, Schumpetrian cycles of innovation and diffusion are observed in the product market when there is price competition. Their result shows that an increase in the rate of diffusion enhances the pace of innovation up to a certain point and has ambiguous effect on R\&D incentives for price competition; the reverse results follow under quantity competition.

Then De Bondt (1997) observes that general spillover possibilities discourage R\&D due to free riding by rivals; however, it can create incentives for $R \& D$ as $R \& D$ efforts by one firm induces other firms to undertake similar endeavours and thus all of them may end up producing at lower costs leading to lower prices and therefore enhanced demand. Very recently, Bakhtiari and Breunig (2018) have provided an empirical study to examine the effect of spillovers on firm level R\&D expenditure in Australia. They have identified both positive and negative effects of spillovers. They have shown that although 
generally negative effects dominate positive effects, but interestingly there are cases when the spillovers may encourage firm level R\&D expenditure. This happens when firms are located within a geographical distance and engaged in complementary research. Thus spillovers from other firms' R\&D enhance the probability of success of a firm's R\&D. This induces the firm to invest more in research.

R\&D incentives under incomplete information is relatively a less trodden area. There are, However, a few interesting works. For instance, Conti (2014) has investigated the role of asymmetric information in the context of RJVs in a duopoly market in presence of spillovers. The paper considers a situation where firms are symmetric initially, but they differ in terms of their R\&D abilities leading to inter-firm asymmetry after the R\&D. The paper, however, deals with one sided asymmetry, i.e. only one firm has private information about its R\&D ability. Then, the paper by Frick et.al. (2016) considers a duopoly where firms decide both R\&D investment levels and entry time, that is when to introduce the new product in the market in an incomplete information framework. The firms differ in terms of their $\mathrm{R} \& \mathrm{D}$ abilities and thus the earliest date at which a prototype can be created varies across firms. This earliest date is private information to a firm. Whichever firm succeeds in developing the prototype first takes away the whole profit. Observability of the rival's R\&D activity plays no role in the decision regarding R\&D investment in this model. In a recent paper Chatterjee et.al. (2017) have studied R\&D incentive of a firm under both sided information asymmetry, but with no spillovers. Therefore, our present paper may be considered an extension of the earlier paper to the case where there are spillovers of $R \& D$ results, but the extent of $R \& D$ spillovers is private information. We are yet to see any work that discusses R\&D incentive of a firm in the presence of spillover of knowledge and the spillover parameters are unknown to the firms.

Existence of spillovers generally reduce $R \& D$ incentives in a complete information framework as noted earlier, with the exception of Bakhtiari and Breunig (2018). But contrary to common wisdom, we have shown that with incomplete information about R\&D spillovers, R\&D incentives may go up under certain situations. If the rival has lower spillover parameter, the concerned firm will be willing to invest because of the 
lower leakage of knowledge. Similarly, if the rival has high spillover parameter, it will be discouraging for the concerned firm to invest. On the other hand, if a firm has a large spillover parameter, it will have less incentive to invest in R\&D because it will tend to benefit from spilled over knowledge from the rival. Under incomplete information a firm does not know with certainty whether the rival has a high or low spillover parameter, although it knows its own spillover parameter, hence it is possible that in its estimate the firm might find R\&D investment profitable. Obviously, the source of enhanced incentive for R\&D in the presence of spillovers as identified in our present paper is completely different from that in Bakhtiari and Breunig (2018).

The organisation of the paper is as follows. Section 2 discusses the model setup. Sections 3 and 4 elaborate the complete information scenario in the absence and presence of R\&D spillovers respectively. Then section 5 considers the incomplete information scenario and section 6 compares the results for complete and incomplete information scenarios. Finally, section 7 concludes the paper. Some calculations are relegated to appendix.

\section{Model Setup}

We consider a Cournot duopoly. The firms are denoted by $A$ and $B$. The inverse demand function of the market is given by $P=\max \{0, a-Q\}$, where $a>0$ and $Q$ is the aggregate output produced in the market. Firms have constant and positive marginal cost denoted by $c$.

Firms are deciding to invest in a cost reducing $\mathrm{R} \& \mathrm{D}$. The cost of the $\mathrm{R} \& \mathrm{D}$ is $H>0$ and same for both the firms. If a firm undertakes $R \& D$, then its marginal cost becomes $c-D$ with certainty, where $0<D<c$. We further assume $a>c+D$, for technical reasons.

Suppose firm $j$ invests in R\&D but firm $i$ does not; then a part of the R\&D result will spill over to firm $i$. The amount spilled over to firm $i$ is denoted by $d_{i}$. So the marginal cost of firm $i$ after the spillover is $c-d_{i}$. Clearly $d_{i} \in[0, D]$ for all $i \in\{A, B\}$. We assume that $d_{i}$ is distributed with the distribution function $F(\cdot)$ and continuous density 
function $f(\cdot)$ and has full support. Therefore, $d_{i}$ also denotes the type of firm $i$ and is private information to firm $i$ in case of incomplete information. It is assumed that firm $i$ knows its own type, before deciding on the R\&D activity ${ }^{4}$.

Consider the following notations: $W:=a-c, q(x):=\frac{W+x}{3}, \Pi(x):=q^{2}(x)$ and $\Psi(x):=\int_{x}^{D} y \frac{d F(y)}{1-F(x)}$. Here, $\Psi(x)$ represents the average value of $y$ conditional on the fact that $y$ lies between $x$ and $D$. Thus $y$ represents the conditional expectation of the rival's type when the type of a particular firm is $x$, and the rival's type lies above its own type $x$ (and definitely below the upper limit of the interval $D$ ). Note that $q^{\prime}>0$, $\Pi^{\prime}(x)=\frac{2}{3} q(x)>0, \lim _{x \rightarrow D} \Psi(x)=D$ and $\Psi^{\prime}(x)>0$ when $x \in(0, D)$. Denote 'doing research' by $R$ and 'no research' by $N$. Suppose firm $A$ chooses to invest in research and firm $B$ does not, then we denote profit (expected profit) of the firm $A$ by $\Pi_{A}^{[R N]}\left(E \Pi_{A}^{[R N]}\right)$ and that of firm $B$ by $\Pi_{B}^{[R N]}\left(E \Pi_{B}^{[R N]}\right)$. Similar notation will be used for other cases.

Our objective is to find out how the decision of performing the research is dependent on the type of the firm and the level of information available to it. So we construct a two stage game. In the first stage each firm decides whether or not to invest in research. And in the second stage they compete in the product market.

\section{Complete Information With No Spillover}

If a firm invests in research then its marginal cost is $c-D$, otherwise it is $c$.

\section{Lemma 1.}

a. If none of the firms invests in research, then each firm has a profit of $\Pi(0)$.

b. If both of them invest in research, then each of them has a profit of $\Pi(D)-H$.

c. If firm $i$ invests in research and firm $j$ does not, then the profit of firm $i$ is $\Pi(2 D)-H$ and the profit of firm $j$ is $\Pi(-D)$.

From the above lemma we find that if the rival is not doing research, then it is always optimal for firm $i$ to do research if and only if $\Pi(2 D) \geq \Pi(0)+H$, that is, if and only if

\footnotetext{
${ }^{4}$ In this paper we are not endogenising $d_{i}$, but it is a parameter known to firm $i$.
} 
$\frac{4(W+D) D}{9} \geq H$. Second, if the rival firm is doing research, then firm $i$ will do research if and only if $\Pi(D) \geq \Pi(-D)+H$, that is, if and only if $\frac{4 W D}{9} \geq H$. These are summarised in the following proposition.

\section{Proposition 1.}

a. Both of them will invest in research if $\frac{4 W D}{9} \geq H$.

b. None of the will invest in research if $\frac{4 D(W+D)}{9} \leq H$.

c. Only one of them will invest in research if $\frac{4 W D}{9}<H<\frac{4 D(W+D)}{9}$. $^{5}$

\section{Complete Information With Spillover}

We assume in this section that everything is common knowledge, including the types of the firms. Since we are considering a duopoly, at equilibrium any of the following three cases can happen: (1) both the firms invest in R\&D, (2) none of the firms invests in R\&D and (3) one firm invests and the other does not. The lemma below summarizes the payoffs of a firm under different equilibrium situations.

Lemma 2. Given two firms $i$ and $j, i, j \in\{A, B\}$ and $i \neq j$,

a. If none of them invests in research then each of them gets $\Pi_{i}^{[N N]}=\Pi_{j}^{[N N]}=\Pi(0)$.

b. If both of them invest in research then each of them gets $\Pi_{i}^{[R R]}=\Pi(D)-H$.

c. Suppose firm $i$ invests in research and firm $j$ does not, then, $\Pi_{i}^{[R N]}=\Pi\left(2 D-d_{j}\right)-$ $H$ and $\Pi_{j}^{[R N]}=\Pi\left(2 d_{j}-D\right)$.

The payoffs of the players for different combinations of strategies are given below.

From above, first note that if the rival is not doing research then it is always optimal for firm $i$ to do research if and only if $\Pi\left(2 D-d_{j}\right) \geq \Pi(0)+H$, that is, if and only if $d_{j} \leq 2 D-\left(\sqrt{W^{2}+9 H}-W\right)$. Second, if the rival firm is doing research then firm $i$ will do research if and only if $\Pi(D) \geq \Pi\left(2 d_{i}-D\right)+H$, that is, if and only if $d_{i} \leq \frac{\sqrt{(W-D)^{2}+(4 W D-9 H)}-(W-D)}{2}$. These two cases simply tell that if the type of a firm is

\footnotetext{
${ }^{5}$ The model does not predict which of the firms will invest in research in this scenario.
} 


\begin{tabular}{|c|c|c|}
\hline Firm A Firm B & $\mathrm{R}$ & NR \\
\hline $\mathrm{R}$ & $\Pi(D)-H, \Pi(D)-H$ & $\Pi\left(2 d_{B}-D\right), \Pi\left(2 D-d_{B}\right)-H$ \\
\hline NR & $\Pi\left(2 D-d_{A}\right)-H, \Pi\left(2 d_{A}-D\right)$ & $\Pi(0), \Pi(0)$ \\
\hline
\end{tabular}

Table 1: Payoff matrix under complete information

sufficiently small, it is then better for the firm to invest in research since the spillover effect is small.

Note that if $H>\frac{4 W D}{9}$, then both firms will never do research simultaneously. In particular if $H \geq \frac{4(W+D) D}{9}$ then none of them will invest in research.

In this case either none of them will invest in research or only one of them will invest in research. Following Roy Chowdhury (2005), we may define:

Strategic Incentive : The strategic incentive for R\&D is firms $i$ 's payoff from R\&D, net of its payoff from not doing R\&D, when firm $j$ invests in R\&D.

Non-strategic Incentive: The non strategic incentive for R\&D is firms $i$ 's payoff from $R \& D$, net of its payoff from not doing $R \& D$, when firm $j$ does not invested in R\&D.

Then, for firm $i$, we have

i. Non-strategic incentive of $\mathrm{R} \& \mathrm{D}$ without spillover is $N(W)=\Pi(2 D)-\Pi(0)-H$.

ii. Non-strategic incentive of R\&D with spillover is $N(S)=\Pi\left(2 D-d_{j}\right)-\Pi(0)-H$.

iii. Strategic incentive of $\mathrm{R} \& \mathrm{D}$ without spillover is $S(W)=\Pi(D)-\Pi(-D)-H$.

iv. Strategic incentive of R\&D with spillover is $S(S)=\Pi(D)-\Pi\left(2 d_{i}-D\right)-H$.

Clearly $N(W) \geq N(S)$ and $S(W) \geq S(S)$. Therefore, both strategic and nonstrategic R\&D incentives in the presence of spillovers are lower compared to the case of no spillovers. Hence we have the following proposition.

Proposition 2. Under complete information, the presence of spillovers reduces $R \mathscr{E} D$ incentives. 


\section{Incomplete Information}

In this section we consider the problem under incomplete information about spillover parameters, hence we assume that $d_{i}$ is private information to firm $i(i=A, B)$. Note that each firm knows its type before it decides its R\&D investment. Since R\&D decision is taken at the first stage, therefore, at the beginning of the production stage, each firm knows from the realisisation of $d_{i}$ whether its rival has invested in R\&D or not. Let us assume that there exists a threshold value of spillover parameter, $\delta$, such that a firm will invest in research if and only if its type (i.e. its spillover parameter) is less than or equal to $\delta$. Therefore, given the cost of the research (i.e. $H$ ), our primary objective in this section would be to find out $\delta$.

Like the case of complete information we start our analysis by finding out the (expected) payoffs of firms under different situations. The following lemma derives the (expected) profits.

\section{Lemma 3.}

a. If none of the firms has invested in research, then each of them gets $\Pi_{A}^{[N N]}=\Pi_{B}^{[N N]}=$ $\Pi(0)$.

b. If both of them have invested in research, then they both get $\Pi_{i}^{[R R]}=\Pi(D)-H$.

c. Suppose firm $A$ does the research and firm $B$ does not, then

$$
\Pi_{A}^{[R N]}=\Pi(2 D-\Psi(\delta))-H \quad \text { and } \quad \Pi_{B}^{[R N]}=\Pi\left(\frac{3 d_{B}+\Psi(\delta)}{2}-D\right) .
$$

Proof. See Appendix I.

When firm $i$ is doing research, but it does not know whether firm $j$ is doing research or not, then its expected profit is $(1-F(\delta)) \Pi(2 D-\Psi(\delta))+F(\delta) \Pi(D)-H$. On the other hand, if firm $i$ is not doing research and it does not know whether firm $j$ is doing research or not, then its expected profit is $(1-F(\delta)) \Pi(0)+F(\delta) \Pi\left(\frac{3 d_{i}+\Psi(\delta)}{2}-D\right)$. Therefore, firm $i$ will invest in $\mathrm{R} \& \mathrm{D}$ if the former expression is greater than the latter. 
Let $T(x ; \delta)$ denote the "gross" opportunity "gain" from doing research when the type of the firm is $x$. Then $T(x ; \delta)$ can be defined as

$$
T(x ; \delta):=(1-F(\delta))[\Pi(2 D-\Psi(\delta))-\Pi(0)]+F(\delta)\left[\Pi(D)-\Pi\left(\frac{3 x+\Psi(\delta)}{2}-D\right)\right]
$$

Note that given $\delta, T(x ; \delta)$ is decreasing in $x$. Also, $T(0 ; 0)=\Pi(2 D-\Psi(0))-\Pi(0)$ and with slight abuse of notation let $T(D ; D):=\lim _{x \rightarrow D} T(x ; x)=0$. So $T(0 ; 0)>T(D ; D)$. Finally, $\delta$ has to be solved from the equation $T(\delta ; \delta)=H$.

As stated above, our objective is to find out $\delta$ as a function of $H$. However, note that till now there is nothing that tells us that for a particular $H$ there will be a unique $\delta$. The following lemma ensures the uniqueness.

Lemma 4. $T(x ; x)$ is strictly decreasing in $(0, D)$.

Proof. See Appendix I.

The following proposition states the conditions for pooling and separating equilibria.

\section{Proposition 3.}

a. If $H \leq T(D ; D)$, then all the firms will invest in research.

b. If $H \geq T(0 ; 0)$, then no firm will invest in research.

c. Finally, when $T(D ; D)<H<T(0 ; 0)$, there exists a unique $\delta$ such that a firm will invest in research if and only if its type is less than or equal to $\delta$ when $\delta$ can be obtained by solving the equality $T(\delta ; \delta)=H$.

The uniqueness of $\delta$ given $H$ in the third result is straight from Lemma 4 as illustrated in the following figure.

Note that given any $H$, the critical $\delta$ is obtained from $T(\delta, \delta)=H$, i.e. $\delta=\delta(H)$.

In the second stage if a firm does not invest in $R \& D$, it can perfectly know from the realisation of its spillover parameter whether the other firm has invested in R\&D. Now, if a firm has a high spillover parameter, it has less incentives to perform R\&D. Two forces are operating. First, if a firm is of high type it is always prone to wait for the spillover 


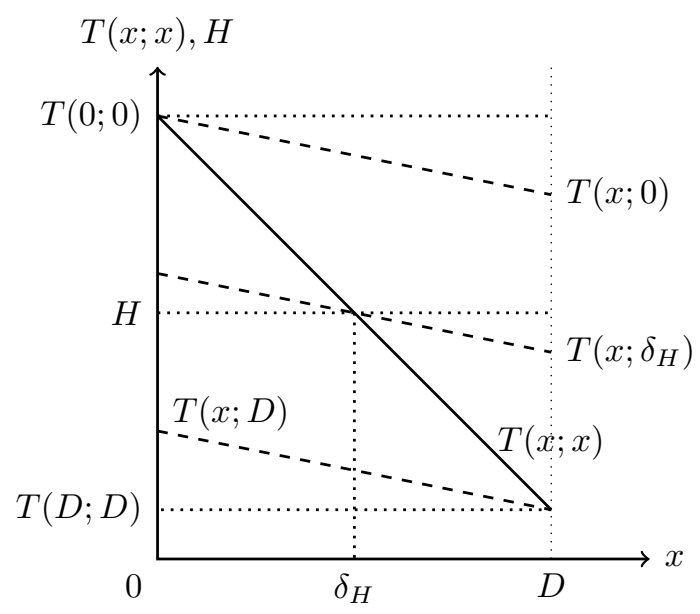

Figure 1: Determination of the Critical Spillover Parameter $\delta$

benefits resulting form its rival's R\&D. On the other hand, a firm which is of high type, if it expects its rival to be of high as well, the firm under consideration will be discouraged to perform R\&D considering the possibility of free-riding by its rival. Thus, the act of performing R\&D itself acts as a signal of a firm's types, since it is an indication of the low type of the firm performing R\&D.

So, it is important now to check the incentive compatibility. We claim that a firm will invest in R\&D if and only if the type of the firm is less than or equal to $\delta$. Suppose firm $A$ follows this strategy and believes firm $B$ to be also following the same strategy. Firm $B$ knows firms $A$ 's strategy and belief. We can have the following observations.

Observation 1. Suppose firm $B$ 's type is greater than $\delta$ but it decides to invest in R\&D. Here from the second stage onwards firm $A$ believes that the type of firm $B$ is less than $\delta$. So, firm $A$ will produce accordingly.

So the expected profit of firm $B$ is $(1-F(\delta)) \Pi(2 D-\Psi(\delta))+F(\delta) \Pi(D)-H$. However, if it had not invested, then its expected profit would have been $(1-F(\delta)) \Pi(0)+$ $F(\delta) \Pi\left(\frac{3 d_{B}+\Psi(\delta)}{2}-D\right)$.

From the definition of $\delta$, and since $T(x ; \delta)$ is strictly decreasing in $x$, we know that for all $d_{B}>\delta$ the following holds:

$$
\begin{aligned}
& {\left[(1-F(\delta)) \Pi(0)+F(\delta) \Pi\left(\frac{3 d_{B}+\Psi(\delta)}{2}-D\right)\right]} \\
& \quad \geq[(1-F(\delta)) \Pi(2 D-\Psi(\delta))+F(\delta) \Pi(D)-H] .
\end{aligned}
$$


So, if firm $B$ 's type is greater than $\delta$, then given firm $A$ 's strategy and belief, it will never invest in research.

Observation 2. Suppose firm B's type is less than or equal to $\delta$ but it decides not to invest in R\&D. Here from the second stage onwards firm $A$ believes that the type of firm $B$ is greater than $\delta$. So, firm $A$ will produce accordingly.

So the expected profit of firm $B$ is $(1-F(\delta)) \Pi(0)+F(\delta) \Pi\left(\frac{3 d_{B}+\Psi(\delta)}{2}-D\right)$. However, if it had invested then its expected profit would have been $(1-F(\delta)) \Pi(2 D-\Psi(\delta))+$ $F(\delta) \Pi(D)-H$.

Again from the definition of $\delta$, and since $T(x ; \delta)$ is strictly decreasing in $x$, we know that for all $d_{B} \leq \delta$ the following holds:

$$
\begin{aligned}
& {[(1-F(\delta)) \Pi(2 D-\Psi(\delta))+F(\delta) \Pi(D)-H]} \\
& \quad \geq\left[(1-F(\delta)) \Pi(0)+F(\delta) \Pi\left(\frac{3 d_{B}+\Psi(\delta)}{2}-D\right)\right] .
\end{aligned}
$$

So, if firm $B$ 's type is less than or equal to $\delta$ then, given firm $A$ 's strategy and belief, it will always invest in research.

By optimal strategy under incomplete information we mean that the firm will invest in $R \& D$ if and only if the type is less than or equal to $\delta$ and believes that the rival is following the same strategy. The above two observations show that given that the rival is following the optimal strategy mentioned above, it is always optimal for a firm to follow the same strategy. So, both the firms following this strategy is a perfect Bayesian Nash equilibrium.

Below we illustrate the above findings.

Example 1. Let us assume $a=10, c=2, D=1$ and $H=2$. Also assume $d_{i}$ 's are distributed uniformly. So, $W=8, f(x)=1, F(x)=x, \Psi(x)=\frac{1+x}{2}$. We have $\Pi(0)=\frac{64}{9}$, $\Pi(D)=9, \Pi\left(2 d_{i}-D\right)=\frac{\left(7+\frac{7 d_{i}+1}{4}\right)^{2}}{9}$ and $\Pi\left(2 D-d_{i}\right)=\frac{\left(10-\frac{1+d_{i}}{2}\right)^{2}}{9}$. Firm $i$ is indifferent between investing and not investing in research if and only if

$$
\left(1-d_{i}\right)\left[\left(10-\frac{1+d_{i}}{2}\right)^{2}-64\right]_{14}+d_{i}\left[81-\left(7+\frac{7 d_{i}+1}{4}\right)^{2}\right]=18
$$


holds. Therefore, $\delta \approx 0.5107$. If research cost is more than 2.917 then no firm will invest in research. On the other hand if there is no research cost then both the firms will always invest in research.

\section{Comparison between Complete and Incomplete Information}

To compare the results under incomplete and complete information, we basically need to compare the threshold values under these two situations. It is important to note that in case of complete information the threshold value depends on the type of the rival firm, whereas in case of incomplete information it does not. So to compare we must first fix the type of the rival firm.

Under incomplete information a firm will invest in R\&D if and only if its type is below the threshold value $\delta$, where $\delta$ is derived from $T(\delta ; \delta)=H$.

Under complete information firm $i$ will invest in $\mathrm{R} \& \mathrm{D}$ if $\Pi\left(2 D-d_{j}\right)-\Pi(0)>H$ and $\Pi(D)-\Pi\left(2 d_{i}-D\right)>H$. So whether a firm is investing in R\&D depends only on $\delta$ in case of incomplete information, but it depends on both $d_{A}$ and $d_{B}$ under complete information. Consider the following two examples.

Example 2. Suppose $d_{i}$ s are distributed with the distribution function $d_{i}^{2}$ over the interval $[0,1]$, therefore $D=1$. Let $a=10$ and $c=2$, so $W=8$. Let $H=2.3$, so $\delta \approx 0.4238$. Assume $d_{B}=0.9$ and $d_{A}=0.41$. Clearly, firm $A$ will invest in research in case of incomplete information. However in case of complete information irrespective of whether the other firm is investing in research or not firm $A$ will never invest in research.

Example 3. Suppose $d_{i}$ s are distributed with the distribution function $d_{i}^{2}$ over the interval $[0,1]$, therefore $D=1$. Let $a=10$ and $c=2$, so $W=8$. Let $H=2.43$, so $\delta \approx 0.3213$. Assume $d_{B}=\Psi(\delta)$ and $d_{A}=0.33$. Clearly, firm $A$ will not invest in research in case of incomplete information. However in case of complete information irrespective of whether the other firm is investing in research or not firm $A$ will always invest in research.

From these two examples it is quite clear that under certain situations incomplete information may give incentives for $R \& D$ when there are spillovers of $R \& D$ results. The 
following proposition summarises this finding.

Proposition 4. There are situations when spillovers are present, under incomplete information R\&D incentives are higher compared to complete information.

Note that under incomplete information a firm does not know the type of its rival. So the firm may invest in R\&D even if the type of its rival is very high. However, under complete information the firm knows the type of its rival, so it may not find it profitable to invest in $\mathrm{R} \& \mathrm{D}$ under complete information.

\section{Conclusion}

This paper examines $R \& D$ incentives of a firm in the presence of spillovers of $R \& D$ output to the rivals, but the extent of cost reduction due to spillovers is private information to the firms. We have considered a duopoly framework and constructed a two-stage game where the firms decide in the first stage whether they will invest in R\&D or not, then in the second stage the firms play Cournot game. If a firm invests in R\&D, it comes up with the fixed size of innovation (marginal cost reduction) with certainty, but given that there is a possibility of spillover of knowledge, even if a firm does not invest in $R \& D$, it can still experience a cost reduction due to spillovers from $R \& D$ results of the rival. However, if both the firms invest in $R \& D$, there is no additional benefit to accrue to a firm due to spillovers. Therefore, in the presence of automatic spillovers of R\&D outcome, as considered in the paper, every firm gets to learn whether the rival has performed R\&D or not when the concerned firm does not conduct R\&D by itself. When the firms are aware of each other's spillover parameters, we are in a complete information framework. However, if the extent of spillover is private information, that is, the concerned firm knows its spillover parameter, but the rival does not, we are in the world of incomplete information. Hence the spillover parameters constitute types of the firms. We have considered general distribution function of types. We have shown that the presence of spillover reduces R\&D incentive of a firm unambiguously under complete information, but interestingly, and contrary to the common wisdom, we have shown that under incomplete information R\&D incentive of a firm may go up. Thus our result supports De 
Bondt (1997), but for different reasons. In De Bondt (1997) spillovers can create incentive for R\&D because R\&D efforts by one firm induces other firms to lower costs leading to lower prices and enhanced demand. De Bondt (1997) calls this 'market expansion effect'. In the context of our model, with complete information about the rival's capability to benefit from spillovers, if the rival has lower value of spillover parameter, the concerned firm will be willing to invest because of the lower leakage of knowledge. On the other hand, if the rival has high spillover parameter, it will be discouraging for the concerned firm to invest. But under incomplete information when it does not know with certainty whether the rival has high or low spillover parameter, the concerned firm, in its estimate, may find R\&D investment profitable. Thus, our result generalizes De Bondt's (1997) incentive creating effort of spillover in an incomplete information scenario.

In our paper we have R\&D outcome to be certain. Hence one meaningful extension of the present work should be to include uncertainty in the realization of the R\&D outcome, and then to study the question of R\&D incentive of a firm in the presence of both spillovers and uncertainty of $\mathrm{R} \& \mathrm{D}$ outcome under various informational structures. Endogenising the size of the innovation may be another possible extension. 


\section{References}

[1] Amir, R. , I. Evstigneev and J. Wooders (2003), "Noncooperative versus cooperative R\&D with endogenous spillover rates", Games and Economic Behavior, 42(2), 183207.

[2] Baker, S., and C. Mezzetti (2005), "Disclosure as a Strategy in the Patent Race", The Journal of Law and Economics , 48(1), 173-194.

[3] Bakhtiari, S. and R. Breunig (2018), "The role of spillovers in research and development expenditure in Australian industries", Economics of Innovation and New Technology, 27(1), 14-38.

[4] Baye, M. R., and H. C. Hoppe (2003), "The strategic equivalence of rent-seeking, innovation, and patent-race games", Games and Economic Behavior , 44(2), 217-226.

[5] Chatterjee, R., S. Chattopadhyay and T. Kabiraj (2017), "R\&D in a Duopoly under Incomplete Information", International Journal of Economic Theory, (Forthcoming).

[6] Conti, C. (2014), "Asymmetric information in a duopoly with spillovers: new findings on the effects of RJVs" (No. 2013-04), http://wp.demm.unimi.it/files/wp/2013/ DEMM-2013_04wp.pdf.

[7] d'Aspremont, C., and A. Jacquemin (1988), "Cooperative and noncooperative R\&D in duopoly with spillovers", The American Economic Review, 78(5), 1133-1137.

[8] De Bondt, R. (1997), "Spillovers and innovative activities", International Journal of Industrial Organization, 15(1), 1-28.

[9] Frick, A., H.C. Hoppe-Wewetzer and G. Katsenos (2016), "R\&D and market entry timing with incomplete information", https://editorialexpress.com/cgi-bin/ conference/download.cgi?db_name=EEAESEM2016\&paper_id=838. 
[10] Ghosh S. and S. Ghosh (2014), "Are Cooperative R\&D Agreements Good For The Society?", Journal of Business 8 Economics Research Fourth Quarter 2014, 12 (3), 313-322.

[11] Griliches, Z. (1992), "The Search for R\&D Spillovers", The Scandinavian Journal of Economics, 94, 29-47.

[12] Jaffe, A.B. (1986), "Technological Opportunity and Spillovers of R\&D: Evidence from Firms' Patents, Profits and Market Value", The American Economic Review, 76(5), 984-1001.

[13] Kamien, M. I., E. Muller, and I. Zang (1992), "Research joint ventures and R\&D cartels", The American Economic Review, 1293-1306.

[14] Katz, M. L. (1986), "An analysis of cooperative research and development", The RAND Journal of Economics, 17, 527-543.

[15] Kogut, B. and U. Zander (1992), "Knowledge of the firm, a combinative capabilities and the replication of technology", Organization Science, 3(3), 383-397.

[16] Mookherjee, D., and D. Ray (1991), "On the competitive pressure created by the diffusion of innovations", Journal of Economic Theory, 54(1), 124-147.

[17] Ornaghi, C. (2006), "Spillovers in product and process innovation: Evidence from manufacturing firms", International Journal of Industrial Organization , 24(2), 349380.

[18] Reinganum, J.F. (1981), "Market Structure and the Diffusion of New Technology", The Bell Journal of Economics, 12(2), 618-624.

[19] Roy Chowdhury, P.(2005), "Patents and R\&D: the tournament effect",Economics Letters , 89(1), 120-126.

[20] Shapiro, C. (1985), "Patent licensing and R\&D rivalry", The American Economic Review, 75(2), 25-30. 
[21] Suzumura, K. (1992), "Cooperative and Noncooperative R\&D in an Oligopoly with Spillovers", The American Economic Review, 1307-1320.

\section{Appendices}

\section{Proof of Lemma 3}

Proof. The expected profit of firm $A$ and $B$ are respectively

$$
E \Pi_{A}^{R N}=(K+D) q_{A}-q_{A}^{2}-q_{A} \int_{\delta}^{D} \frac{q_{B}(y) d F(y)}{1-F(\delta)}
$$

and

$$
E \Pi_{B}^{R N}=\left(K+d_{B}\right) q_{B}-q_{B}^{2}-q_{B} q_{A}
$$

The corresponding reaction functions are

$$
(K+D)-2 q_{A}-\int_{\delta}^{D} \frac{q_{B}(y) d F(y)}{1-F(\delta)}=0 \quad \text { and } \quad\left(K+d_{B}\right)-2 q_{B}-q_{A}=0 .
$$

Solving the two reaction functions stated above we get

$$
q_{A}=q(2 D-\Psi(\delta)) \quad \text { and } \quad q_{B}=q\left(\frac{3 d_{B}+\Psi(\delta)}{2}-D\right)
$$

The rest of the proof is trivial. 


\section{Proof of Proposition 4}

Proof. We have

$$
\begin{aligned}
9 T(x ; x)= & (1-F(x))\left[K^{2}+2 K(2 D-\Psi(x))+(2 D-\Psi(x))^{2}-K^{2}\right] \\
& +F(x)\left[K^{2}+2 K D+D^{2}-K^{2}-2 K\left(\frac{3 x+\Psi(x)}{2}-D\right)-\left(\frac{3 x+\Psi(x)}{2}-D\right)^{2}\right] \\
= & (1-F(x))\left[2 K(2 D-\Psi(x))+(2 D-\Psi(x))^{2}\right] \\
& +F(x)\left[2 K D+D^{2}-2 K\left(\frac{3 x+\Psi(x)}{2}-D\right)-\left(\frac{3 x+\Psi(x)}{2}-D\right)^{2}\right] \\
= & 2 K(2 D-\Psi(x))+(1-F(x))(2 D-\Psi(x))^{2} \\
& +F(x)\left[D^{2}+2 K \Psi(x)-2 K D-2 K\left(\frac{3 x+\Psi(x)}{2}-D\right)-\left(\frac{3 x+\Psi(x)}{2}-D\right)^{2}\right] \\
& 2 K D+D^{2}-F(x)\left[2 K\left(\frac{3 x+\Psi(x)}{2}-D\right)+\left(\frac{3 x+\Psi(x)}{2}-D\right)^{2}\right] \\
& +2 K(D-\Psi(x))(1-F(x))+(1-F(x))\left[2 D(D-\Psi(x))+(D-\Psi(x))^{2}\right]
\end{aligned}
$$

Now it can be easily seen that $\frac{d}{d x} 9 T(x ; x)<0$. This completes the proof. 